\title{
RELATIVE DISPLACEMENTS OF 3D OPTICAL MARKERS FOR DEFORMATIONS AND CRACK MONITORING OF A MASONRY STRUCTURE UNDER SHAKING TABLE TESTS
}

\author{
IVAN ROSELLI ${ }^{1}$, GERARDO DE CANIO $^{1}$, MICHELA ROSSI $^{2}$, CHIARA CALDERINI $^{2}, \&$ \\ SERGIO LAGOMARSINO ${ }^{2}$ \\ ${ }^{1}$ ENEA Italian National Agency for New Technologies, Energy and Sustainable Economic Development, Italy. \\ ${ }^{2}$ Department of Civil, Chemical and Environmental Engineering, University of Genoa, Italy.
}

\begin{abstract}
The application of 3D motion capture systems to shaking table testing provides a unique tool for recording relative displacements of a large number of measurement points of the tested structure. The analysis of 3D relative displacements during dynamic tests allows us to evaluate the structure deformations and to monitor the cracks formation and evolution. The present paper focuses on the processing and analysis of 3D motion capture data to extract accurate displacements between markers positioned on a full-scale model of a masonry cross vault representing a vault of the mosque of Dey, Algiers, tested at the ENEA Casaccia Research Centre. The management and processing of the data acquired through 67 markers located on the vault are described, showing the potentialities of the methodology. Moreover, the possible formulation of damage indices based on the structure deformations and cracks aperture detected from markers relative displacements (MRDs) was explored. In particular, cracks could be counted and classified as a function of the detected apertures, following damage thresholds indicated in the Italian regulations. Moreover, the failure mechanism could be easily visualized and analysed by monitoring the cumulative MRDs. In addition, in-plane and out-of-plane deformations of walls could be monitored during each seismic test, providing accurate information on the torsional and bending effects.
\end{abstract}

Keywords: 3D motion capture, crack, deformations, masonry structures, shaking table tests.

\section{INTRODUCTION}

The assessment of the structural damage that occurs in buildings under seismic loads is a very difficult task and it becomes even more complex in the case of historic masonry structures, since this construction typology generally presents heterogeneous and little known materials with highly nonlinear behaviour. Different approaches can be applied depending on the main objective and scale of the assessment. In post-earthquake damage surveys of large areas, mainly qualitative and speedy approaches are used in order to classify immediately buildings that require repair and/or strengthening, and to identify which ones are irretrievable [1-2]. In such circumstances, structural engineers are usually provided with simplified damage assessment forms prepared to guide them in only-visual inspections and intended to be filled with qualitative descriptions and few synthetic quantitative data.

When focusing their attention on a single structure, experts can make use of a variety of non-destructive techniques by in-situ instrumentations for a more accurate and quantitative characterization of the damage level [3-4]. Even more accurate evaluations can be obtained by integrating such in-situ measurements with laboratory tests on the material properties of samples, when it is possible to extract some.

In experimental studies, it is particularly important to evaluate the damaging processes of structures for academic and scientific purpose, for example, through shaking table testing of structural prototypes. In these cases, the damage processes can be analysed with the most detailed and accurate methods available and controlled environment.

A crucial role is played by the description of the crack pattern and of the deformations in the structure, as from such information it is possible to derive the identification of the 
activated collapse mechanisms and to estimate their severity [2]. To such purpose a widely recognized international standard for damage assessment is the European Macroseismic Scale EMS-98 [5], which entails the classification into five damage levels described as: (1) negligible to slight damage, (2) moderate damage, (3) substantial to heavy damage, (4) very heavy damage, and (5) destruction. The above general subdivision is then more explicitly detailed for each building typology, providing also quantitative elements of interpretation and specific descriptions of the damage levels. The above European standard is also adopted by the Italian regulation [6].

For a more quantitative assessment of damage a variety of indices were defined by several authors for different construction typologies. Damage indices are commonly constructed on the basis of structural or dynamic prosperities, such as the displacements, the energy dissipation and the stiffness reduction of the structure subjected to dynamic excitation [7-9]. Such indices are calculated in the damage analysis of structures through numerical models, but in the case of real constructions they are difficult to estimate. With this in mind, however, cracks and deformations can be studied for localization and quantification of damage. In particular, the crack pattern and the plastic deformations can be monitored by using modern techniques capable of tracking the position of a large number of measurement points of the structure recorded before and after the seismic event. This can be achieved in practice with the use of machine vision technologies [10]. In laboratory environment, for example, 3D motion capture systems [11] have been recently applied to shaking table tests with successful results both on scaled models [12-13] and on full-scale masonry structures [14].

\section{INSTRUMENTATION}

In the present section, a description of the instrumentation used for the experimental tests is provided. In particular, the opto-electronic measurement system for displacement detection and the seismic testing facility are illustrated.

\section{$2.13 \mathrm{D}$ displacement measurement system}

The displacements of the structure under seismic test were measured through a passive 3D motion capture system. This machine vision-based technology is based on a constellation of high-frequency and high-resolution cameras located around the studied object. The cameras illuminate their field of view with near-infrared light-emitting diode strobes and acquire the radiation retro-reflected by cheap spherical markers covered with retro-reflecting sheeting positioned at the desired measurement points of the structure.

Each camera is provided with on-board processing to calculate the $2 \mathrm{D}$ image coordinates of each marker's centroid and related radius. After geometric calibration of the cameras, the markers centroid and radius data are processed through triangulation algorithms in order to reconstruct the $3 \mathrm{D}$ positions of the measurement points. The current configuration of the system has 10 Vicon cameras, 7 of which are V5 cameras and 3 are Bonita type [15]. The system is able to achieve an overall accuracy in terms of relative mean square error of markers position in the order of $0.01-0.1 \mathrm{~mm}$, depending on the specific acquisition geometry [16].

An example of acquisition geometry is shown in Fig. 1. Cameras are located out of the reaction mass area, because during seismic tests it undergoes slight movements that would induce further motion measurement errors. As usual for seismic applications, data were acquired at $200 \mathrm{fps}$ (i.e. $200 \mathrm{~Hz}$ of sampling frequency). 


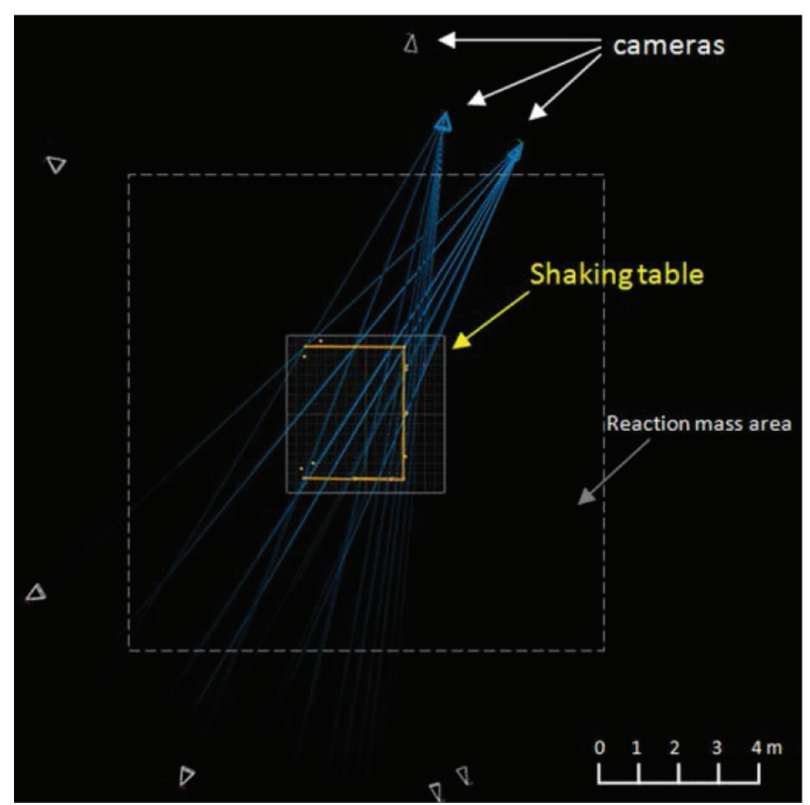

Figure 1: Typical acquisition geometry of the 3D displacement measurement system at the ENEA shaking table laboratory (plan view).

\subsection{Shaking table facility}

The seismic tests analysed in the present paper were carried out on the largest of the two shaking tables available at the seismic hall of the ENEA Casaccia research centre, located near Rome, Italy. The main technical specifications and capacity of the utilized shaking table are shown in Table 1. It is capable of reproducing strong-motion earthquakes with peak ground acceleration (PGA) higher than $1 \mathrm{~g}$ on full-scale two-storey buildings or similar mock-ups with an overall height of up to $6 \mathrm{~m}$.

Table 1: ENEA Casaccia shake tables technical specifications.

\begin{tabular}{lcc}
\hline Parameter & System 1 & System 2 \\
\hline Table size & $4 \times 4(\mathrm{~m})$ & $2 \times 2(\mathrm{~m})$ \\
Degrees of freedom & 6 & 6 \\
Frequency range & $0-50(\mathrm{~Hz})$ & $0-100(\mathrm{~Hz})$ \\
Acceleration & $3 \mathrm{~g} \mathrm{peak}$ & $5 \mathrm{~g}$ peak \\
Velocity & $0.5 \mathrm{~m} / \mathrm{s}(0$-peak $)$ & $1 \mathrm{~m} / \mathrm{s}(0-$ peak $)$ \\
Displacement & $0.125 \mathrm{~m}(0-$ peak $)$ & $0.15 \mathrm{~m}(0-$ peak $)$ \\
Specimen mass & $30(\mathrm{t})$ & $5(\mathrm{t})$ \\
\hline
\end{tabular}

Note: The shaking table utilized in the present experimentation is System 1. 


\section{ANALYSIS OF MARKERS RELATIVE DISPLACEMENTS}

The used instrumentation makes possible to detect the 3D position of more than a hundred measurement points of the studied structure. This implies that all the points of interest where cracks and deformations may arise, such as members' connections and joints, can be monitored with an appropriate positioning of the markers on the structure. Analysing the relative displacements between couples of markers, the cracks can be detected, localized and characterized in $3 \mathrm{D}$, also providing information on the modes of fractures.

The triaxial components of markers relative displacements (MRDs) may also change in the case of rotation of the structural member in the 3D space, so deformations and cracks of rigid body are better detected through changes in markers distances (MDs) [12].

\subsection{Dynamic and residual displacements}

MRDs and MDs time-histories can be analysed in order to extract their dynamic behaviour during each seismic test. When MD time-histories present peaks beyond a given threshold, then a crack is detected. In previous studies, a threshold of around $0.2 \mathrm{~mm}$ proved to be effective in detecting the smallest cracks arising during shaking table tests [12]. Cracks may close at the end of the seismic event and limited or no residual MD increase is revealed. This is the case of hairline cracks associated with the initial damage of the structure. Higher levels of residual MD increase indicate a greater plastic deformation of the structure. It is worth noting that in post-earthquake inspections the observed cracks are residual openings by definition, so their width must be compared with the measured residual MD increases after shaking table tests.

\subsection{Damage assessment}

With reference to the most recent Italian regulations [6], post-earthquake damage in masonry structures is classified in function of crack location and width. In particular, two width thresholds are indicated ( $5 \mathrm{~mm}$ and $20 \mathrm{~mm}$ ) to distinguish between 'severe' or 'very severe' damage. Two additional thresholds at $0.5 \mathrm{~mm}$ and $1 \mathrm{~mm}$ were considered to classify small and medium cracks, respectively.

In terms of damage indices, different kinds of properties (structural or dynamic), at different scale (local or global), may be take into account. Moreover, considering fatigue effects, cumulative or non-cumulative indices can be built. For example, several damage indices based on structural properties, such as displacements history or hysteretic curves, were proposed in the literature [17], but their validity was mainly proved for reinforced concrete structures and depends on parameters calibration in experimental tests. Additionally, damage indices based on the dynamic properties of the structures are commonly used [18]. They are essentially built as a function of modal parameters. In particular, global damage indices are constructed on the basis of change in the fundamental frequency of the structure, making the assumption that damage processes induce a sensible reduction of the system's stiffness. A widely used damage index of this kind is the following:

$$
D I_{f}=1-\frac{f_{d}^{2}}{f_{0}^{2}} \text {. }
$$

where $f_{0}$ is the initial fundamental frequency of the undamaged structure and $f_{d}$ is the fundamental frequency of the damaged structure. Frequencies can be extracted through experimental modal analysis (EMA) methods, such as the ones based on the computation of the frequency 
response function (FRF) of the structure, or other modal identification methods [19]. In the FRF computation, instruments located on the structure are taken as output signal, while instruments on the shaking table are considered for the input signals.

In the present study, a damage index derived from MD measurements is also explored. For simplicity, it was defined as a global residual deformation (GRD) index and it is calculated as a summation of the MD per cent increments, i.e. of the plastic deformations, between all the considered couples of markers. It can be formulated as follows:

$$
G R D=\sum_{i=1}^{n}\left(\frac{\Delta M D_{i}}{M D_{i}}\right)
$$

where $n$ is the number of the considered couples of adjacent markers. The more the markers positions cover well the overall volume of the structure, the more the GRD index is representative of the global state of damage. The proposed index will be compared with $D I_{f}$ for validation of results. A possible refinement of the above index is a formulation that take into account the different contributions of portions of the structure to the global behaviour, for example, by the use of a weighted average index [18]. Weights can be used to differentiate the relevance of structural members and/or collapse mechanisms that can develop during the damage process. However, in such formulations the definition of proper weights becomes quite crucial and controversial, while it complicates the final computation.

\section{SEISMIC TESTS}

In the following subsections a description of the experimental application to a case study carried out on a cross vault prototype subjected to seismic tests is shown.

\subsection{Specimen}

The tested specimen represented one of the 10 cross vaults of the Mosque of Dey, a sixteenth-century private mosque of the king of Algiers, located in the Citadel of Algiers. The cross vaults, along with five small domes, are placed along the 20-m square perimeter of the mosque. On the external side, the cross vaults present a $36-\mathrm{cm}$ thick wall. On the inner side, marble columns support pointed arches that define a central area covered by an octagonal dome. All the vaulted structures are made of baked clay bricks assembled with lime mortar.

The prototype cross vault (Fig. 2(a)) is one brick layer in thickness and its dimensions are 350 $\times 360 \mathrm{~cm}^{2}$ square plan, with a total height of $565 \mathrm{~cm}$. The pointed arch is reinforced by a couple of wooden ties. An interesting constructive detail is the insertion of wooden logs of Thuya, a typical wood of the Atlas mountain region, between the vault's springing and the column [20-21]. However, the mock-up was built without the columns, in order to purposely avoid their influence on the dynamic response of the vault. The vault stiffness was reproduced by partially substituting the masonry wall with a reinforced concrete frame with two steel diagonal bracings. The geometry and features of the abutments accurately replicated the real ones. The four corner supports of the cross vault on side A were built within the arch spandrel, while on side $\mathrm{C}$ they are within the thickness of the wall. The edge of the vault's webs was not interlocked with the spandrel and the wall, but it was just placed side by side to them. The vault's prototype was tested either with (WT) and without ties (NT) that were made up of two steel longitudinal bars linking wall C with wall A.

The material properties of the prototype intended to be representative of the historic Algerian masonry, a poor masonry with weak joints. In particular, common baked clay bricks of size $3.5 \times 12 \times 25 \mathrm{~cm}^{3}$ were used, while the joints were $2.5-\mathrm{cm}$ thick. 


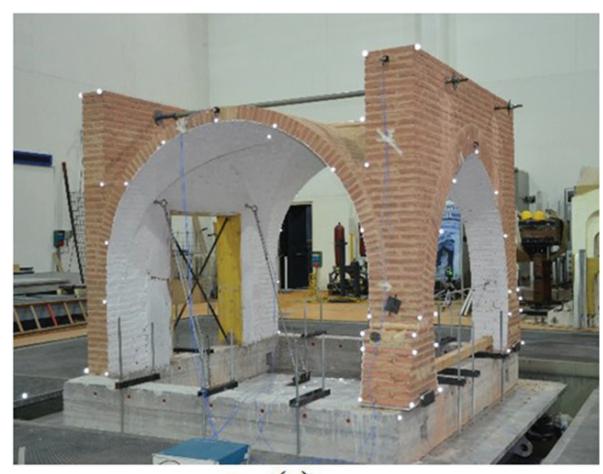

(a)

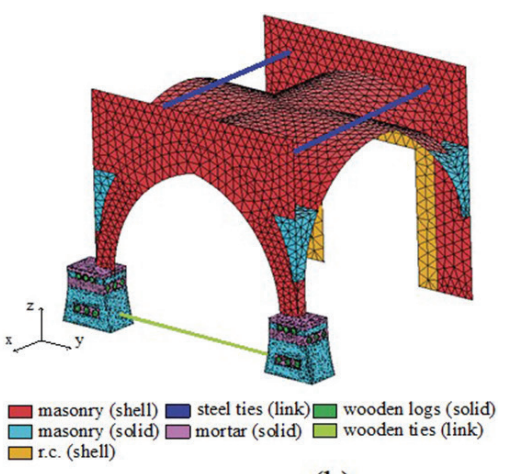

(b)

Figure 2: Tested specimen (a) and FEM model geometry and mesh (b).

The mortar reproduced the properties obtained from characterization tests on mortar samples extracted from buildings of the Citadel, dating back to the same period of construction of the mosque. Clay, finely bricks, gravel, sand, lime and pozzolana in varying proportions were the main components of the samples. Seven mortar specimens with different component's ratios were tested to determine their compression strength $\left(\mathrm{f}_{\mathrm{m}}\right)$ and tensile strength $\left(\tau_{\mathrm{m}}\right)$, according to UNI EN 1015-11:2007 indications. The average values of the mechanical parameters were $\mathrm{f}_{\mathrm{m}}$ equal to $3.74 \mathrm{MPa}$, and $\tau_{\mathrm{m}}$ equal to $1.18 \mathrm{MPa}$.

The mortar joint's shear strength was also evaluated by performing a triplet test on a masonry specimen, obtaining $0.015 \mathrm{MPa}$. Through a compression test performed on a masonry prism $\left(25 \times 25 \times 50 \mathrm{~cm}^{3}\right)$, the values of the compressive strength resulted of $4.4 \mathrm{MPa}$ and elastic modulus of $327 \mathrm{MPa}$. The vault's mock-up was built by assembling bricks according to ancient master builders' solutions observed in historical cross vaults. In order to interlock the vault's webs properly, bricks had to be cut appropriately. The key bricks were placed in the middle of each vault's webs and then, they were stressed by means of wooden shims.

A finite element model (Fig. 2(b)) was created by using ANSYS software. Shell elements were adopted to model the masonry wall, the arch spandrels and the vault, while the four vault's corners built within the thickness of the wall and the spandrels were modelled as 3D solid elements.

Brick elements were also used to model the two masonry abutments with their wooden logs and the mortar around them. The steel and the wooden ties were modelled by using link elements. The model's materials and their properties in terms of Young's modulus $\mathrm{E}_{\mathrm{x}}$, Poisson's ratio $v$ and density $\rho$ are shown in Table 2 .

Table 2: Mechanical properties of the materials of the tested prototype.

\begin{tabular}{lccc}
\hline Material & $\mathbf{E}_{\mathbf{x}}(\mathbf{M P a})$ & $v$ & $\rho\left(\mathbf{k g} / \mathbf{c m}^{\mathbf{3}}\right)$ \\
\hline Masonry & 320 & 0.2 & 1800 \\
Mortar & 150 & 0.2 & 1600 \\
r.c. & 40000 & 0.2 & 2500 \\
Wood & 10000 & 0.2 & 500 \\
Steel & 210000 & 0.2 & 7850 \\
\hline
\end{tabular}


In Fig. 3 the positions of the 67 markers acquired by the 3D motion capture system are illustrated. The number of markers is particularly dense close to the abutments in order to detect possible cracks and deformations caused by the wooden logs. Numerous markers were also located along the arches of the vault, while very few markers were positioned at the side-B wall, which is expected to be the stiffest and most resistant part of the prototype. Four accelerometers (in red in Fig. 3) are also used for acceleration monitoring and calibration of makers' data.

\subsection{Input sequence}

The seismic input for shaking table tests was based on the NS component of the ground motion recorded at Keddara station during the 21-May-2003 earthquake occurred in the province of Boumerdes and the eastern part of Algiers with 6.8 Magnitude [22].

In the following, this component will be coded as ked_NS. The input was scaled in intensity and applied mono-directionally along the y-direction. The acceleration time history reproduced by the shake table and the related elastic response spectrum are shown in Fig. 4(a) and Fig. 4(b), respectively. The above signal was normalized and rescaled to the site of the Citadel of Algiers according to the uniform hazard response spectrum (UHRS) method. The mock-up was subjected to a seismic sequence performed with increasing PGA by nominal steps of $0.05 \mathrm{~g}$, as shown in Table 3, along with the effective peak table acceleration (PTA).

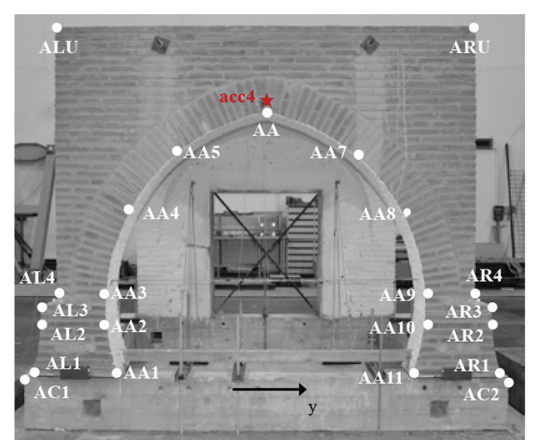

(a)

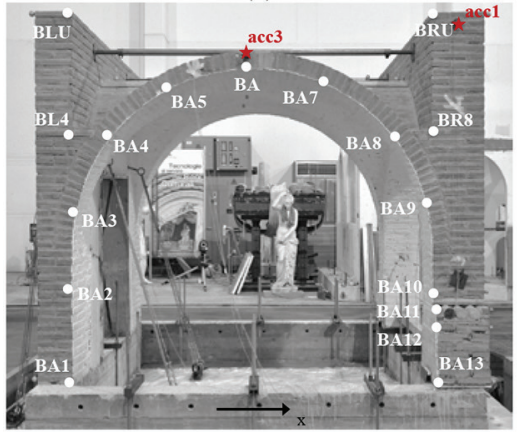

(c)

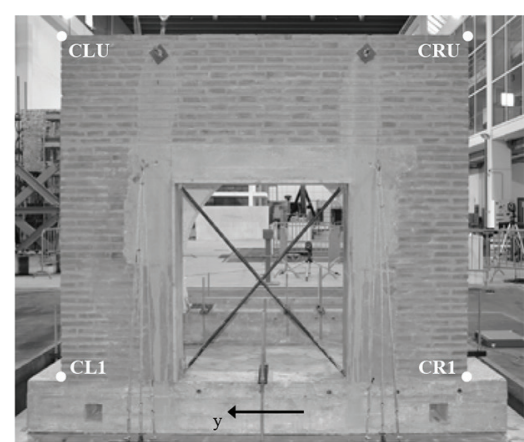

(b)

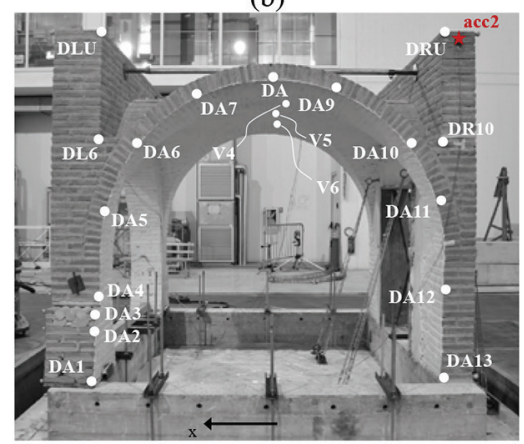

(d)

Figure 3: Positions of markers of the 3D displacements system in side A (a), B (b), C (c) and D (d) of the prototype. The accelerometers are shown in red. 


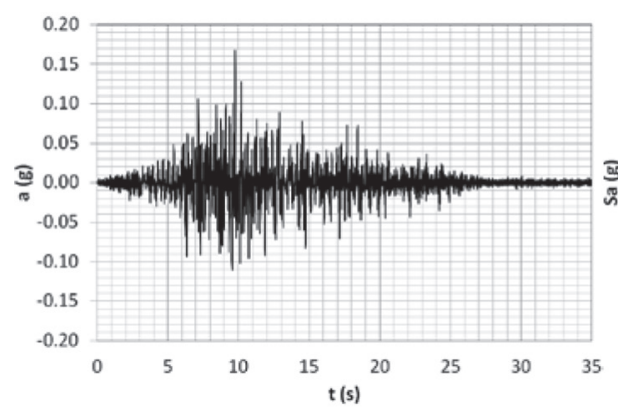

(a)

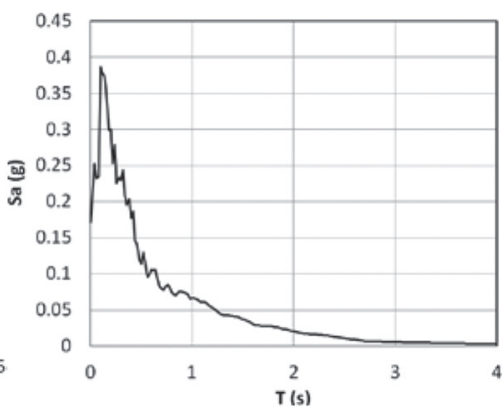

(b)

Figure 4: Seismic input rescaled at $0.10 \mathrm{~g}$ of nominal PGA: effective acceleration time history (a) and elastic response spectrum (b).

Table 3: Seismic sequence of shaking table tests on the prototype with ties (WT) and without ties (NT). PGA is nominal, PTA is the peak table acceleration.

\begin{tabular}{|c|c|c|c|c|}
\hline Test WT & PGA (g) & PTA (g) & Test directions & Damage \\
\hline rnd & 0.01 & 0.012 & $\mathrm{y}$ & Characterization \\
\hline ked_NS_0.05 & 0.05 & 0.065 & $\mathrm{y}$ & No damage \\
\hline ked_NS_0.10 & 0.10 & 0.172 & $\mathrm{y}$ & $\begin{array}{l}\text { Very light } \\
\text { damage }\end{array}$ \\
\hline rnd & 0.01 & 0.012 & $\mathrm{y}$ & Characterization \\
\hline ked_NS_0.15 & 0.15 & 0.262 & $\mathrm{y}$ & $\begin{array}{l}\text { Very light } \\
\text { damage }\end{array}$ \\
\hline rnd & 0.01 & 0.012 & $\mathrm{y}$ & Characterization \\
\hline
\end{tabular}

\begin{tabular}{lcccc}
\hline Test NT & PGA [g] & PTA [g] & Test directions & Damage \\
\hline rnd & 0.01 & 0.012 & $\mathrm{y}$ & Characterization \\
ked_NS_0.10 & 0.10 & 0.173 & $\mathrm{y}$ & Very light dam- \\
ked_NS_0.15 & 0.15 & 0.226 & $\mathrm{y}$ & Light damage \\
ked_NS_0.20 & 0.20 & 0.318 & $\mathrm{y}$ & Heavy damage \\
rnd & 0.01 & 0.012 & $\mathrm{y}$ & Characterization \\
ked_NS_0.25 & 0.25 & 0.398 & $\mathrm{y}$ & Collapse \\
\hline
\end{tabular}

A low-intensity white-noise test (rnd) was carried out before the first seismic test and before the last one to characterize the dynamic behaviour of the mock-up.

5 RESULTS

The markers displacements allowed an effective identification of the activation of the collapse mechanisms in their early stages through an accurate monitoring of the deformed shape. 
The presence of the tie-rods reinforced the vault that presented very limited deformations, as evidence by the blue line in graphs of Fig. 5(a) and Fig. 5(b), which shows the in-plane displacements of the arch springing at side-B and the keystone, respectively. During the tests without ties, the structure exhibited the development of a collapse mechanism since the second shaking table test at $0.226 \mathrm{~g}$ of PTA, evidenced by the increase of the springing's displacements in the x-direction (red line in Fig. 5(a)) and contemporarily the decrease of the keystone height (Fig. 5(b)). The evolution of the overall arch's deformed shape can be seen in Fig 6(a). The mechanism presented the gradual overturning of the side-A wall (Fig 6(b)) in the $x$-direction and the development of three hinges mechanism on the vault.

The hinges formed at the vault's springings, at the vault's crown and at the base of the wall on side A. The corresponding cracks were detected by monitoring the markers displacements. The cracks were characterized according to the classification described in Section 3.2 in function of the openings width, as depicted in Fig. 7, both in terms of dynamic behaviour by peak opening width during each seismic test (a) and of residual opening (b). Applying Eq. (2) the GRD of the structure was calculated (Fig. 8). As shown in Fig. 9, GRD was highly correlated with the consolidated damage index $D I_{f}$ according to Eq. (1) considering the average value of the first modal frequency extracted by FRFs of accelerometers on the structure with reference to the shaking table control accelerometer.

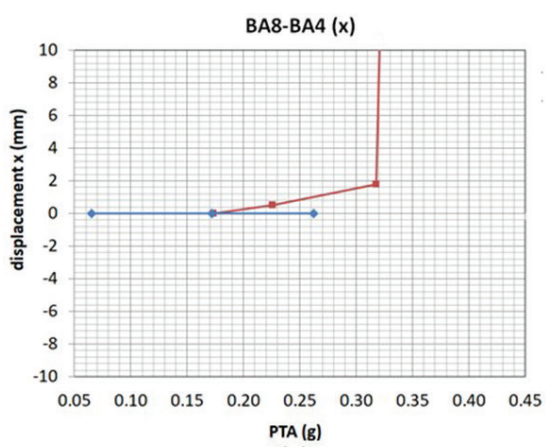

(a)

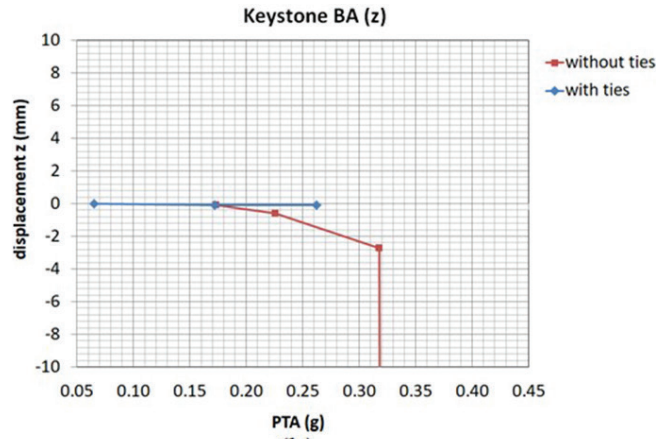

(b)

Figure 5: Relative in-plane displacements between markers BA4 and BA8 at side-B arch imposts (a) and vertical displacements of marker BA at keystone (b).

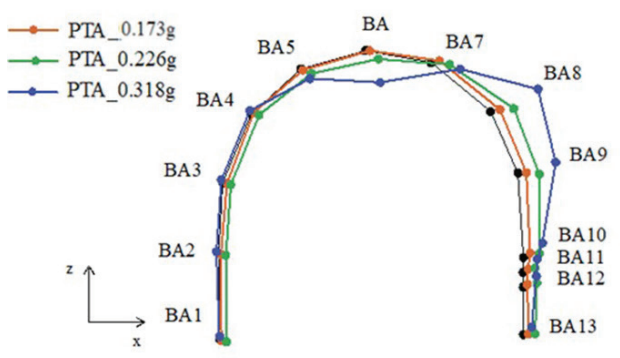

(a)

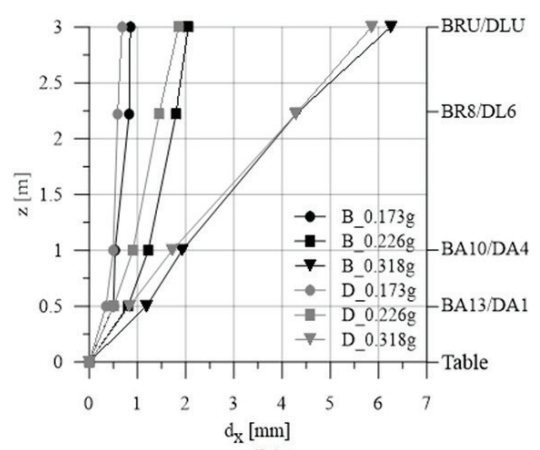

(b)

Figure 6: Deformed shapes of the side-B arch during shaking table tests without ties (a) and out-of-plane displacements in the $\mathrm{x}$-direction $\left(\mathrm{d}_{\mathrm{x}}\right)$ of side-A wall corners on sides B and D (b). PTA is the peak table acceleration. 


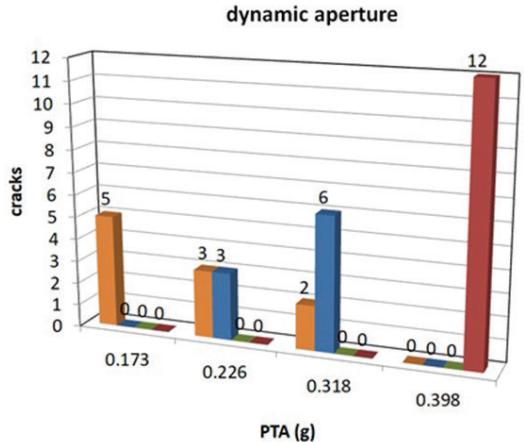

(a)

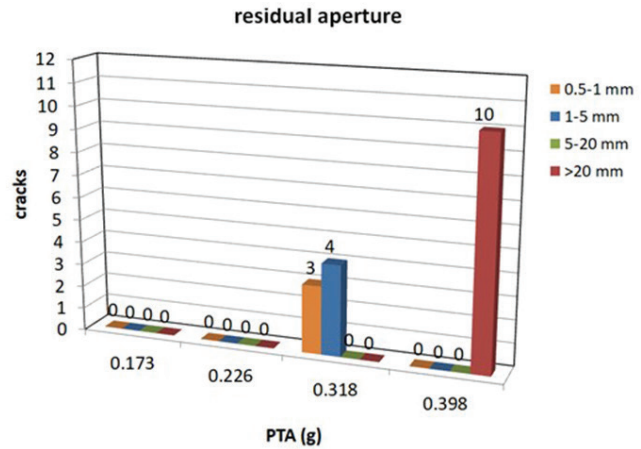

(b)

Figure 7: Number of cracks detected in the vault without ties by maximum opening width during each seismic test (a) and by residual opening (b).

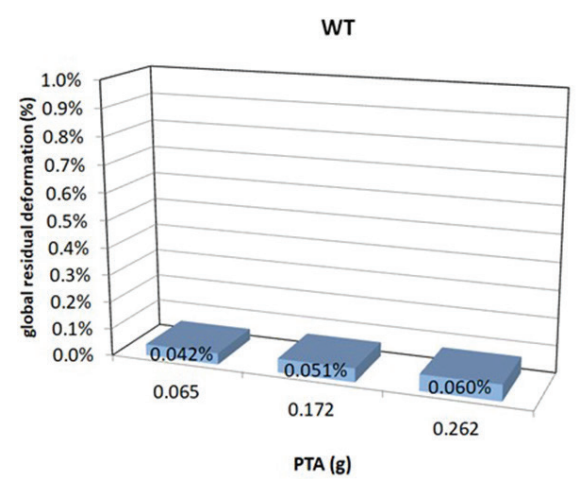

(a)

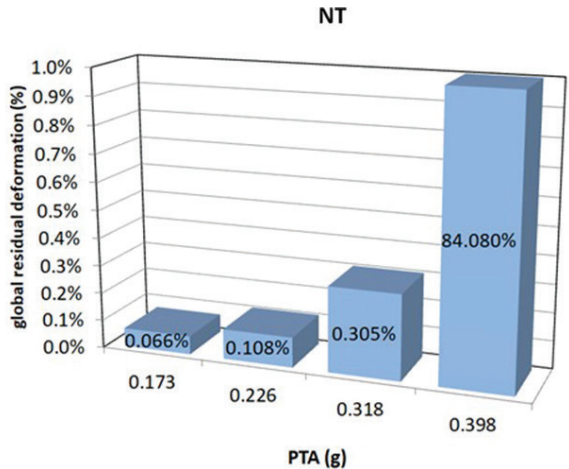

(b)

Figure 8: GRD (\%) of the tested vault with (WT) (a) and without ties (NT) (b).

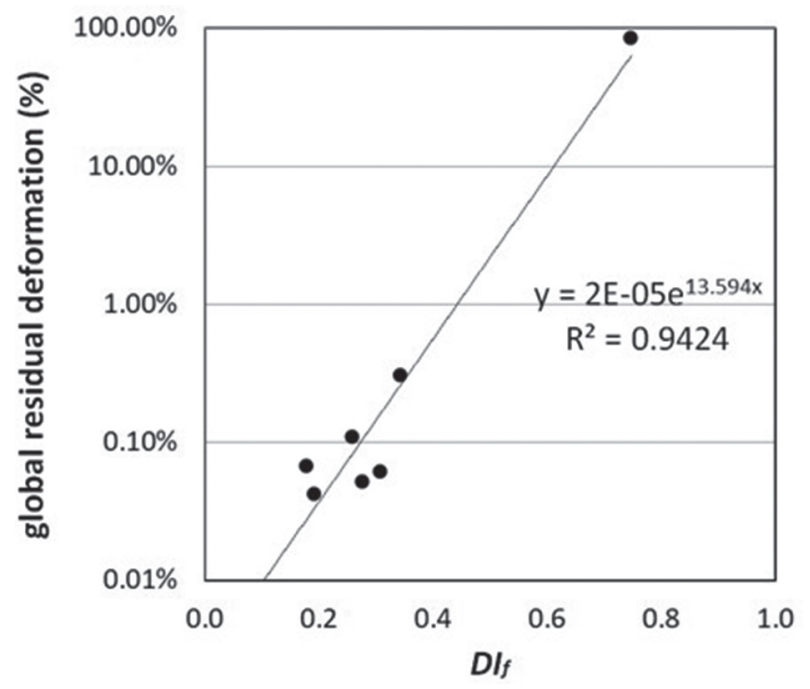

Figure 9: Correlation between GRD (\%) and damage index $D I_{f}$ 


\section{CONCLUSIONS}

The present paper illustrates the potentialities of using the relative displacements of 3D optical markers for the monitoring of deformations and cracks in masonry structures subjected to shaking table tests. A practical application to the study of a cross-vault mock-up is shown. The evolution of the structural deformations could be studied and the collapse mechanisms were recognized and analysed since the early stages of the damage process, when still not visible to the naked eye. Criteria for crack detection and classification, as well as a formulation of a simple global damage index (GRD), on the basis of markers displacements were explored with encouraging results. In particular, the effectiveness of GRD index for damage assessment was validated by comparison with the consolidated $D I_{f}$ index based on the prototype's modal frequencies.

Further studies will be conducted with shaking table experiments on a larger variety of masonry mock-ups in order to improve the proposed damage index with more refined formulations, possibly taking into account the different contributions of portions of the structure. Moreover, using a large amount of markers the methodology showed a remarkable potentiality for crack detection and localization in masonry structures with the perspectives of implementing algorithms for the automatic identification of the collapse mechanisms to be considered for a more appropriate damage assessment formulation.

\section{REFERENCES}

[1] D’Ayala, D. \& Speranza, E., Definition of collapse mechanisms and seismic vulnerability of historic masonry buildings. Earthq Spectra, 19(3), pp. 479-509, 2003. https:// doi.org/10.1193/1.1599896

[2] Lagomarsino, S. \& Podesta, S., Seismic vulnerability of ancient churches: I. Damage assessment and emergency planning. Earthquake Spectra, 20(2), pp. 377-394, 2004. https://doi.org/10.1193/1.1737735

[3] Carpinteri, A., Invernizzi, S. \& Lacidogna, G., In siti damage assessment and nonlinear modelling of a historical masonry tower. Engineering Structure, 27(3), pp. 387-395, 2005. https://doi.org/10.1016/j.engstruct.2004.11.001

[4] Polimeno, M.R., Roselli, I., Luprano, V., Mongelli, M., Tatì, A. \& De Canio, G., A non-destructive testing methodology for damage assessment of reinforced concrete buildings after seismic events. Engineering Structures, 163, pp. 122-136, 2018. https:// doi.org/10.1016/j.engstruct.2018.02.053

[5] Grünthal, G., European Macroseismic Scale 1998 (EMS-98). Cahiers du Centre Européen de Géodynamique et de Séismologie, Helfent-Betrange (Luxembourg) 15, 1998.

[6] OPCM Regulation n. 28, June 9, 2017. Modifiche all'ordinanza n. 19, 7 aprile 2017, recante 'Misure per il ripristino con miglioramento sismico e la ricostruzione di immobili ad uso abitativo gravemente danneggiati o distrutti dagli eventi sismici verificatisi a far data dal 24 agosto 2016'. Gazzetta Ufficiale, (in Italian), Italian standard, 143, June 22, 2017.

[7] Park, Y.J., Ang, A.H.S. \& Wen, Y.K., Seismic damage analysis and damage-limiting design of RC buildings. Structural Research Series, 516, University of Illinois: Urbana, USA. 1984.

[8] Park, Y.J., Ang, A.H.S. \& Wen, Y.K., Damage-limiting aseismic design of buildings. Earthquake Spectra, 3(1), pp. 1-26, 1987. https://doi.org/10.1193/1.1585416 
[9] Roufaiel, M.S.L. \& Meyer C., Analytical modelling of hysteretic behavior of R/C frames. Journal of Structural Engineering, 113(3), pp. 429-444, 1987. https://doi. org/10.1061/(ASCE)0733-9445(1987)113:3(429)

[10] Roselli, I., Fioriti, V., Mongelli, M., Colucci, A. \& De Canio, G., Machine Vision-Based Application to Structural Analysis in Seismic Testing by Shaking Table. Optoelectronics in Machine Vision-Based Theories and Applications, IGI Global ed., 2018. https:// doi.org/10.4018/978-1-5225-5751-7.ch010

[11] De Canio, G., Mongelli, M. \& Roselli, I., 3D Motion capture application to seismic tests at ENEA Casaccia Research Center: 3DVision system and DySCo virtual lab. WIT Transactions on The Built Environment, 134, pp. 803-814, 2013. https://doi. org/10.2495/SAFE13071

[12] Roselli, I., Mongelli, M., Tatì, A., \& De Canio, G., Analysis of 3D motion data from shaking table tests on a scaled model of Hagia Irene, Istanbul. Key Engineering Materials, 624, pp. 66-73, 2015. https://doi.org/10.4028/www.scientific.net/ KEM.624.66

[13] Calderini, C., Lagomarsino, S., Rossi, M., De Canio, G., Mongelli, M. \& Roselli, I., Shaking table tests of an arch-pillars system and design of strengthening interventions by the use of tie-rods. Bulletin of Earthquake Engineering, 13(1), pp. 279-297, 2015. https://doi.org/10.1007/s10518-014-9678-x

[14] De Canio, G., de Felice, G., De Santis, S., Giocoli, A., Mongelli, M., Paolacci, F. \& Roselli, I., Passive 3D motion optical data in shaking table tests of a SRG-reinforced masonry wall. Earthquakes and Structures, 40(1), pp. 53-71, 2016. https://doi. org/10.12989/eas.2016.10.1.053

[15] Vicon documentation, https://docs.vicon.com/display/CamDocs. (accessed January 23, 2019).

[16] Mongelli, M., Roselli, I., De Canio, G. \& Ambrosino, F., Quasi real-time FEM calibration by $3 \mathrm{D}$ displacement measurements of large shaking table tests using HPC resources. Advances in Engineering Software, 120, pp. 14-25, 2018. https://doi.org/10.1016/j. advengsoft.2016.07.005

[17] Williams, M.S. \& Sexsmith, R.G., Seismic damage indices for concrete structures: A state-of-the-art review. Earthquake Spectra, 11(2), pp. 319-349, 1995. https://doi. org/10.1193/1.1585817

[18] DiPasquale, E., Ju, J.W., Askar, A. \& Çakmak, A.S., Relation between Global Damage Indices and Local Stiffness Degradation. Journal of Structural Engineering, 116(5), pp. 1440-1456, 1990. https://doi.org/10.1061/(ASCE)07339445(1990)116:5(1440)

[19] Roselli, I., Fioriti, V., Mongelli, M., Bellagamba, I. \& De Canio, G., Mutual validation between different modal analysis techniques for dynamic identification of the so-called Temple of Minerva Medica, Rome. IOP Conference Series: Materials Science and Engineering, 364, p. 012004, 2018. https://doi.org/10.1088/1757899X/364/1/012004

[20] Abdessemed-Foufa, A., Visual screening for a potential evaluation of seismic vulnerability of historical building: Palace of the Dey (Citadel of Algiers). WIT Transactions on The Built Environment, ed. WIT Press, 123, pp. 119-123, 2012. https://doi.org/10.2495/ DSHF120101 
[21] Abdessemed Foufa, A., Terki, Y. \& Benouar, D., Case study: Local seismic culture in vernacular architecture in Algeria. In Seismic Retrofitting: Learning from Vernacular Architecture, eds. Correia M.R, Lourenco P.B \& Varum H. CRC Press, pp. 101-102, 2015. https://doi.org/10.1201/b18856

[22] Khellafi, A.M., Harichane, Z., Afra, H. \& Sadouki, A., A Case Study of Accelerometric Records Analysis of May 21st, 2003, Boumerdes (Algeria) Earthquake. International Journal of Geotechnical Earthquake Engineering (IJGEE), 4(2), pp. 34-52, 2013. https://doi.org/10.4018/ijgee.2013070103 